OPEN ACCESS

Edited by:

Andy Pereira,

University of Arkansas, United States

Reviewed by: Riccardo Di Mambro, University of Pisa, Italy

Raffaele Dello loio,

Sapienza University of Rome, Italy Capilla Mata Pérez,

University of Jaén, Spain

*Correspondence: Ana M. Laxalt amlaxalt@mdp.edu.ar

Specialty section: This article was submitted to Plant Abiotic Stress, a section of the journal

Frontiers in Plant Science

Received: 27 December 2019 Accepted: 26 June 2020 Published: 21 July 2020

Citation:

Di Fino LM, Cerrudo I, Salvatore SR, Schopfer FJ, García-Mata C and Laxalt AM (2020) Exogenous Nitro-Oleic Acid Treatment Inhibits Primary Root Growth by Reducing the Mitosis in the Meristem in Arabidopsis thaliana. Front. Plant Sci. 11:1059 doi: 10.3389/fpls.2020.01059

\section{Exogenous Nitro-Oleic Acid Treatment Inhibits Primary Root Growth by Reducing the Mitosis in the Meristem in Arabidopsis thaliana}

\author{
Luciano M. Di Fino ${ }^{1}$, Ignacio Cerrudo ${ }^{1}$, Sonia R. Salvatore ${ }^{2}$, Francisco J. Schopfer ${ }^{2}$, \\ Carlos García-Mata ${ }^{1}$ and Ana M. Laxalt ${ }^{1 *}$ \\ 1 Instituto de Investigaciones Biológicas, CONICET-Universidad Nacional de Mar del Plata, Mar del Plata, Argentina, \\ 2 Department of Pharmacology \& Chemical Biology, University of Pittsburgh, Pittsburgh, PA, United States
}

Nitric oxide (NO) is a second messenger that regulates a broad range of physiological processes in plants. NO-derived molecules called reactive nitrogen species (RNS) can react with unsaturated fatty acids generating nitrated fatty acids $\left(\mathrm{NO}_{2}-\mathrm{FA}\right)$. $\mathrm{NO}_{2}$-FA work as signaling molecules in mammals where production and targets have been described under different stress conditions. Recently, $\mathrm{NO}_{2}$-FAs were detected in plants, however their role(s) on plant physiological processes is still poorly known. Although in this work NO2-OA has not been detected in any Arabidopsis seedling tissue, here we show that exogenous application of nitro-oleic acid (NO2-OA) inhibits Arabidopsis primary root growth; this inhibition is not likely due to nitric oxide (NO) production or impaired auxin or cytokinin root responses. Deep analyses showed that roots incubated with $\mathrm{NO}_{2}-\mathrm{OA}$ had a lower cell number in the division area. Although this $\mathrm{NO}_{2}-\mathrm{FA}$ did not affect the hormonal signaling mechanisms maintaining the stem cell niche, plants incubated with $\mathrm{NO}_{2}-\mathrm{OA}$ showed a reduction of cell division in the meristematic area. Therefore, this work shows that the exogenous application of $\mathrm{NO}_{2}-\mathrm{OA}$ inhibits mitotic processes subsequently reducing primary root growth.

Keywords: nitro-oleic acid treatment, nitro-fatty acid, root development, signaling, nitric oxide, Arabidopsis

\section{HIGHLIGHT}

Nitrated fatty acids regulate root development

\section{INTRODUCTION}

The formation of nitrolipids was initially proposed in animals from the observation that nitric oxide (NO) inhibited lipid oxidation propagation reactions (Rubbo et al., 1994). The nitration of fatty acids is induced by species derived from NO (Freeman et al., 2008). In animals, nitrated lipids are signaling molecules, acting as intermediaries in potent cascades of signal transduction, which translate into changes in protein functionality due to post-translational modifications (Batthyany 
et al., 2006; Rubbo and Radi, 2008; Trostchansky and Rubbo, 2008; Schopfer et al., 2011). So far, there are few reports about the detection of $\mathrm{NO}_{2}$-FA in plants. Specifically, adducts between $\mathrm{NO}_{2}$-OA and Cys $\left(\mathrm{NO}_{2}\right.$-OA-Cys) together with nitroconjugated linoleic acid $\left(\mathrm{NO}_{2}\right.$-cLA) were detected in olive fruits and Extra Virgin Olive Oil (EVOO) although nor free $\mathrm{NO}_{2}$-OA was detected in olives (Fazzari et al., 2014). $\mathrm{NO}_{2}$-OA was recently detected in the free fatty acid fraction of seeds and seedlings of Brassica napus (Vollár et al., 2020). Also, nitrolinolenic acid $\left(\mathrm{NO}_{2}-\mathrm{Ln}\right)$ was observed in cell suspension cultures, seeds, seedlings and leaves of the model plant Arabidopsis (Mata-Pérez et al., 2016a) and in important crops such as rice and pea (Mata-Pérez et al., 2016b). Exogenous application of $\mathrm{NO}_{2}$ - $\mathrm{Ln}$ induced both and antioxidant response and the chaperone network in Arabidopsis (Mata-Pérez et al., 2016a) and NO production in Arabidopsis primary root tip (Mata-Pérez et al., 2016c). Exogenous application of nitro-oleic acid $\left(\mathrm{NO}_{2^{-}}\right.$ $\mathrm{OA}$ ) induced reactive oxygen species (ROS) production via activation of NADPH oxidases and not NO production in tomato cell suspensions (Arruebarrena Di Palma et al., 2020). Arabidopsis NADPH oxidase mutants showed that NADPH isoform $\mathrm{D}$ (RBOHD) was required for $\mathrm{NO}_{2}$-OA-induced ROS production in leaves (Arruebarrena Di Palma et al., 2020).

$\mathrm{NO}$ is a well-established second messenger in plants and is involved in the development of the root system. NO regulates processes such as the formation of root hairs in Arabidopsis and lettuce (Lactuca sativa L.) (Lombardo et al., 2006), as well as the formation of adventitious roots via the activation of MAPK in cucumber (Cucumis sativus) (Pagnussat et al., 2004). The root is divided in the mersitematic/division zone, the elongation zone and the differentiation zone. The meristematic cells, a cell type with a high rate of cell division, coordinates the growth and development of the root. In Arabidopsis, NO targets the cells in the elongation zone, inhibiting the cellular elongation mediated by gibberellins (Fernández-Marcos et al., 2012). In addition, NO decreases the levels of the auxin transporters (PINs) in the membrane, affecting the transport and distribution of auxins and altering downstream signaling (Fernández-Marcos et al., 2011). High levels of NO inhibit the development of the primary root, reducing the meristematic zone, directly affecting mitotically active cells (Fernández-Marcos et al., 2011).

Most of the plant hormones (abscisic acid, auxins, cytokinins, ethylene, gibberellins and brassinosteroids) regulate cell division and elongation processes (Benkova and Hejatko, 2009; Wolters and Jürgens, 2009). The root stem cell niche at the root apical meristem is composed of stem cells with high rate of division given rise to specific root cells lineages, which are surrounding a group of cells with a low division rate called the quiescent center (QC) (Scheres, 2007). QC plays an important role in maintaining undifferentiated stem cells (van den Berg et al., 1997). The differentiation of daughters stem cells give rise to several cell types integrating the root architecture, being growth defined by the balance between cell division and elongation (Dolan et al., 1993; Scheres et al., 1994).

In this work we show that $\mathrm{NO}_{2}$-OA inhibits primary root growth. This inhibition is not due to NO signaling, altered auxine/ cytokinin responses or altered mechanism that maintain the stem cell niche. Here we show that exogenous application of $\mathrm{NO}_{2}-\mathrm{OA}$ reduces the cell cycle marker CYCB1:1, resulting in a short meristem.

\section{RESULTS}

\section{$\mathrm{NO}_{2}$-OA Inhibits Primary Root Growth in Arabidopsis}

Arabidopsis seedlings present basal levels of $\mathrm{NO}_{2}$ - $\mathrm{Ln}$ that increase when seedlings are subjected to wounding, cadmium or low temperature stress (Mata-Pérez et al., 2016a). All major nitro lipids share the same electrophilic center, similar reactivity properties and therefore a common mechanism of action (Baker et al., 2004). In animals, $\mathrm{NO}_{2}$-OA has long been used as a surrogate to study and understand the regulation, signaling and metabolism of nitrated fatty acids given its additional stability and well developed synthetic routes (Freeman et al., 2008). We studied the effect of exogenous application of $\mathrm{NO}_{2}-\mathrm{OA}$ on primary root growth of Arabidopsis seedlings. Figure 1 shows dose-dependent inhibition of primary root growth upon $\mathrm{NO}_{2}$ OA treatments compared to untreated or oleic acid (OA) treated seedlings.

The inhibition of the primary root growth could be due to a lower number of cells at the apical meristem and/or a lower cell size or cell elongation rate on the elongation zone of the root. To determine the processes by which $\mathrm{NO}_{2}-\mathrm{OA}$ is modulating root growth, we measured the size and the number of root cells in the meristem. Five-day old Arabidopsis seedlings were treated for another five days with $\mathrm{NO}_{2}$-OA or $\mathrm{OA}$, and the root cells were analyzed by DIC microscopy. The column of cortex cells was counted from the quiescent center (QC) to the last cell where its length was not greater than $50 \%$ compared to the previous one according to what was described in Perilli and Sabatini (2010) (Figure 2A). As shown in Figure 2B control or OA treated roots have an average of $36 \pm 5$ cortex cells in the division zone. $\mathrm{NO}_{2}$ OA-treated roots have a significant reduction in the number of cortex cells (Figure 2B). Roots treated with 12.5 or $25 \mu \mathrm{M}$ of $\mathrm{NO}_{2}$-OA showed an average of $29 \pm 4$ and $19 \pm 4$ cells, respectively. The extension of the meristematic zone was measured as the distance from the QC to the last cell of the division zone (Figure 2C). In control roots, the meristematic zone measures $300 \pm 44 \mu \mathrm{m}$, while $\mathrm{NO}_{2}$-OA treated roots shows a strong reduction of the meristematic zone $(240 \pm 40 \mu \mathrm{m}$ and $180 \pm 22 \mu \mathrm{m}$ for 12.5 or $25 \mu \mathrm{M} \mathrm{NO}_{2}$-OA respectively). The cell size at the elongation zone was not significantly different between treated or not treated roots, being the size of cortical elongated cells $168.8 \pm 2.9,171.3 \pm 2.6$ and $166.7 \pm 1.9 \mu \mathrm{m}$ (mean $\pm \mathrm{SE}, \mathrm{n}=$ 6) for control, $\mathrm{OA}$ and $\mathrm{NO}_{2}$-OA-treated roots, respectively (Figure 2D). A establish balance between cell division and cell differentiation governs meristem size and thus root growth. Since no differences were found in the size of the cells in the differentiation zone, and a reduction of number of cortical cells is observed, then the inhibition of root growth is probably due to a regulation of cell division process. 


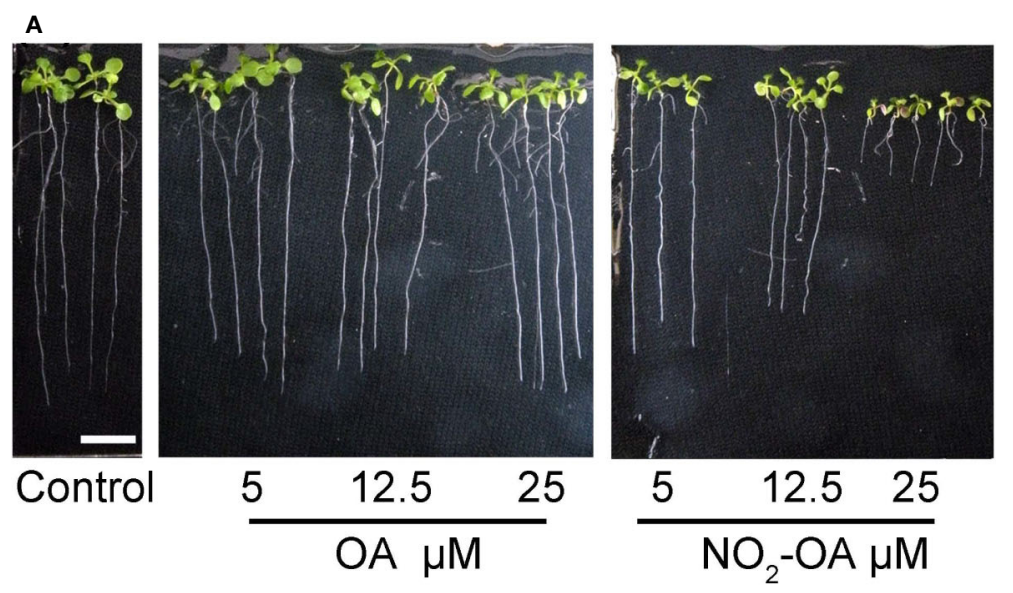

B

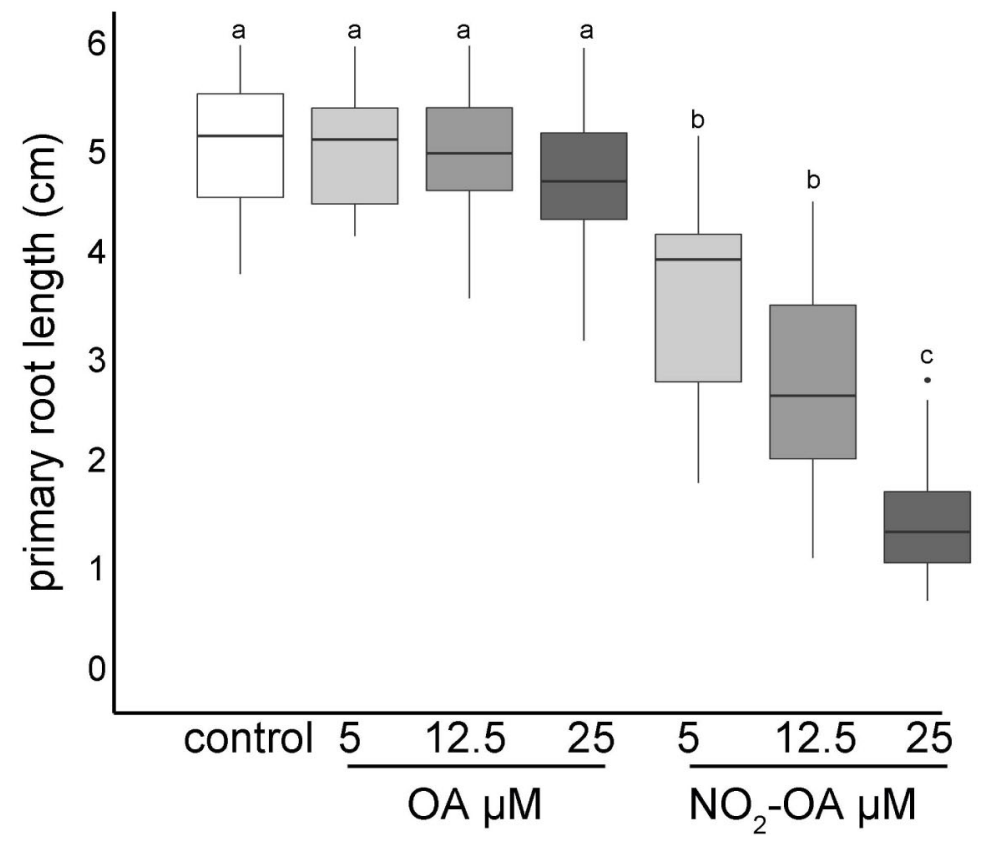

FIGURE 1 | NO $\mathrm{NO}_{2}-\mathrm{OA}$ inhibits primary root growth in Arabidopsis. Seeds were germinated and vertically grown in MS agar for five days, then transferred onto plates with $\mathrm{NO}_{2}-\mathrm{OA}$ or $\mathrm{OA}(25,12.5 \circ 5 \mu \mathrm{M})$ during five days. (A) Representative image of Arabidopsis primary root growth. Scale bar $=1 \mathrm{~cm}$ (B) Primary root length quantification. Data is depicted in box-plot graphs were the box is bound by the 25th to 75th percentile, whiskers span to minimum and maximum values, and the middle line represents the average of five independent experiments. Different letters indicated statistical significant differences, $n=25$ (ANOVA, Tukey $p<0.001$ ).

It has been previously reported that NO inhibits the growth of the primary root in Arabidopsis (Fernández-Marcos et al., 2011). In addition, in Arabidopsis roots and cell suspensions, $\mathrm{NO}_{2}$ - $\mathrm{Ln}$ treatments induced NO production (Mata-Pérez et al., 2016c). Therefore the evidence suggested the $\mathrm{NO}_{2}$-OA might be affecting root growth in a NO-dependent manner. However, the analysis of NO production, using the florescent probe DAF-FM-DA in 25 $\mu \mathrm{M} \mathrm{NO}_{2}-\mathrm{OA}$ treated roots shows no florescence in $\mathrm{OA}$ or $\mathrm{NO}_{2}-$ $\mathrm{OA}$ treated roots (Figure 3). We used $100 \mu \mathrm{M}$ of the NO donor SNP as a positive control in order to confirm the functionality and distribution of the probe within the root. Figure 3 shows an intense and equally distribution of florescence throughout the root tip in SNP treated roots. These results show that $\mathrm{NO}_{2}-\mathrm{OA}$ treatment does not trigger $\mathrm{NO}$ production in Arabidopsis seedlings suggesting that $\mathrm{NO}_{2}-\mathrm{OA}$ is not inhibiting primary root growth via $\mathrm{NO}$ signaling.

\section{$\mathrm{NO}_{2}$-OA Reduces the Number of Mitotic Cells}

A reduction in the number of meristem cells could be due to a hormonal unbalance. Auxin distribution is important in regulating primary root growth. One of the described roles for auxin in the root tip is to maintain the stem cell niche and promote cell division (Grieneisen et al., 2007). In order to study 

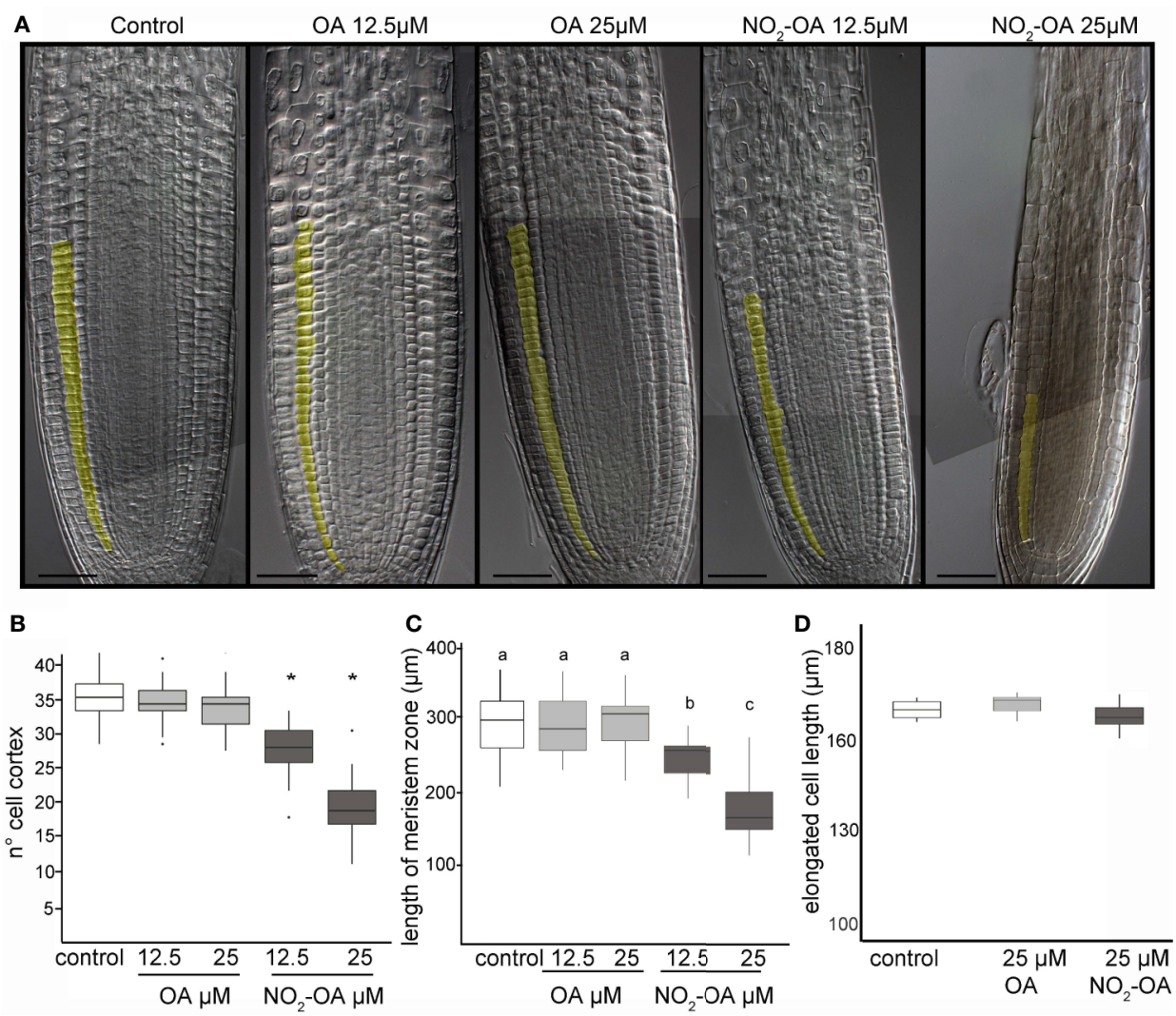

FIGURE 2 | Effect of $\mathrm{NO}_{2}-\mathrm{OA}$ on the Arabidopsis root meristem. Five-day old seedlings were treated with $\mathrm{NO}_{2}-\mathrm{OA}$ or $\mathrm{OA}(25,12.5 \mu \mathrm{M})$ or not treated during other five days. Roots were cleared with Hoyer's solution and observed under DIC microscope. (A) Images of roots from seedlings showing cortex meristem cells artificially colored. Scale bars $=10 \mu \mathrm{m}$. (B) Meristem cell number. Asterisks indicate significant differences from control, $n=30$ ( $p<0.001$, Poisson). (C) Size of root meristem. Different letters indicate statistically significant differences, $n=30$ (ANOVA, Tukey $p<0.001$ ). (D) Total cell size in elongation zone.

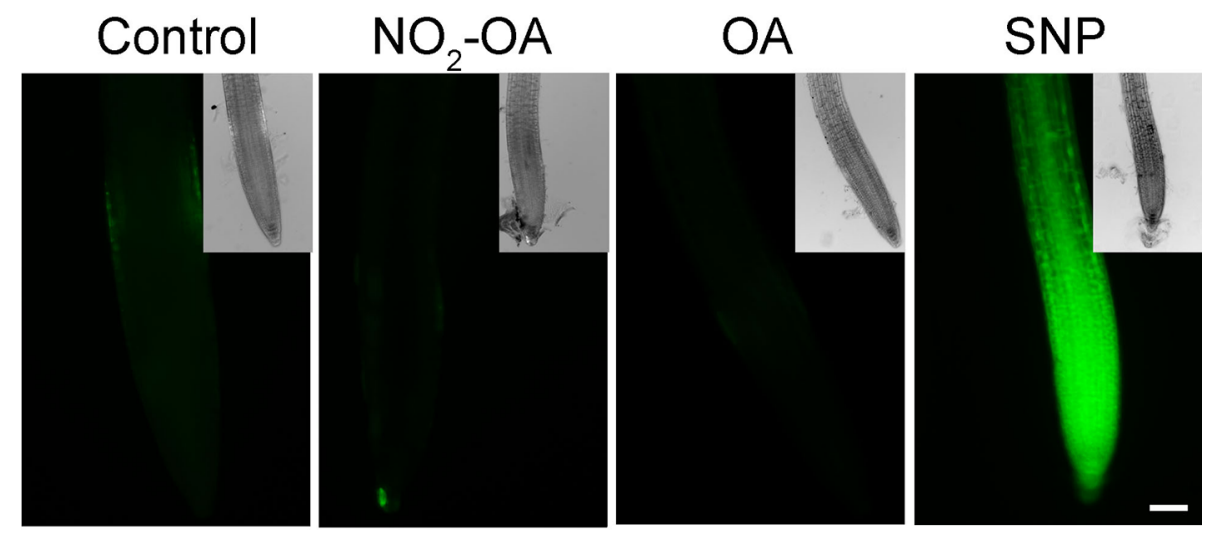

FIGURE 3 | $\mathrm{NO}_{2}$-OA does not trigger $\mathrm{NO}$ accumulation on the meristematic area. Col-0 seedlings were grown for 5 days being after either not-treated or incubated with $25 \mu \mathrm{M} \mathrm{NO}_{2}-\mathrm{OA}$ or OA for five-extra days. Roots were incubated with DAF-FM DA $10 \mu \mathrm{M}$ for 30 min. As positive control for DAF-FM DA probe, roots were treated with $100 \mu \mathrm{M}$ SNP for $30 \mathrm{~min}$. Scale bar $=10 \mu \mathrm{m}$. At least 12 roots were visualized of three independent experiments. 
auxin-response after $\mathrm{NO}_{2}$-OA application, we used Arabidopsis plants with auxin response reporter DR5pro:GUS. DR5pro:GUS activity is observed in the stem cell niche, columella cells and a more subdued staining in vascular tissue in all treatments (Figure 4A). Therefore, this data suggests that auxin responses are not altered because of $\mathrm{NO}_{2}-\mathrm{OA}$ application. In order to confirm the latter result, we used DII-Venus as an independent reporter that shows endogenous auxin abundance, reflecting the input into the auxin-signaling pathway. DII-Venus is a fusion of auxin-dependent degradation domain II of an Aux/IAA protein to Venus fluorescent protein, such that the absence of fluorescence marks auxin accumulation (Brunoud et al., 2012). In agreement with DR5pro:GUS activity, auxin levels (evidenced as the absence of fluorescence) are high in the columella, the quiescent center, and the differentiating xylem cells on control or $12,5 \mu \mathrm{M} \mathrm{NO}$-OA or $\mathrm{OA}$ treated roots (Figure $4 \mathbf{B}$ ). In the meristem zone, from QC to TZ, auxin levels are low in control and OA treated roots, visualized as an intense fluorescence of the DII-Venus protein in the nuclei of the cortex and epidermal cells (Figure 4B). However, when we quantified the fluorescence intensity, $\mathrm{NO}_{2}$-OA treated roots showed less fluorescence compared to OA or non-treated roots (Figure 4C), suggesting an increase in auxin level. However, exogenous application of auxin to wild-type Arabidopsis roots caused an increase in meristem size (Dello Ioio et al., 2007), which is in contraposition to the observed effect that $\mathrm{NO}_{2}$-OA has on root growth. Thus, we cannot discard other explanations for a slight reduction on the fluorescence levels of DII-Venus in $\mathrm{NO}_{2}$-OA treated root cells, especially since DII-Venus is a semiquantitative reporter. Despite that fact, both auxin reporters, DR5pro-GUS and DII-Venus, unequivocally show that $\mathrm{NO}_{2}$-OA does not decrease auxin levels at the stem cells, columella or vascular tissue. Thus, auxin responses (Figure 4A) and levels (Figures 4B, C) are not altered during $\mathrm{NO}_{2}-\mathrm{OA}$ application on stem cells, columella and the differentiating vascular cells.

The role of auxins in root growth is associated with that of their hormone antagonists, cytokinins. It has been described that the size of root apical meristem increases in mutants from the cytokinin synthetic pathway and decreases by the exogenous application of cytokinins (Miyawaki et al., 2004; Dello Ioio et al., 2007). We studied the cytokinin response with the cytokinin reporter TCS : GFP using confocal microscopy (Zürcher et al., 2013; Zürcher et al., 2016) Under control conditions, TCS : GFP is observed at the root tip, particularly in the calyptra (Figure 4D). The roots treated with $\mathrm{NO}_{2}-\mathrm{OA}$ or $\mathrm{OA}$ did not show differences relative to the control (Figure 4E). Altogether the results show that the reduction of meristematic cells in $\mathrm{NO}_{2}-\mathrm{OA}$ treated roots is independent of auxin or cytokinin responses.

Meristematic cells come from stem cells. Stem cells are in a microenvironment, where hormone concentrations and transcription factors play a fundamental role for its maintenance. The root stem cell niches, is formed by the QC and the adjacent stem cell initials (Petricka et al., 2012), which are specified by two parallel pathways: the PLETHORA (PLT) and SHORTROOT (SHR)/SCARECROW (SCR) pathways
(Petricka et al., 2012; Heyman et al., 2014). SCR maintains QC and stem cell identity (Sabatini et al., 2003), in part by inducing the expression of WUSCHEL-RELATED HOMEOBOX5 (WOX5), a QC specific gene (Sarkar et al., 2007). Two types of transcription factors have been well studied regarding the preservation of undifferentiated stem cells, PLETHORA 1 (PLT1, at3g20840) and PLETHORA 2 (PLT2, at1g51190) (Aida et al., 2004; Galinha et al., 2007; Mähönen et al., 2014). High levels of these PLT genes localize in the area of cell division, whilst low PLT levels lead root cells to expand and differentiate The presence and distribution of PLT factors in the root tip regulate the size of the meristem (Aida et al., 2004; Kornet and Scheres, 2009; Mähönen et al., 2014). The expression of PLT1 and PLT2 has been reported to colocalize with the location of auxin in the root tip (Aida et al., 2004; Xu et al., 2006). In order to determine if $\mathrm{NO}_{2}$-OA affects stem cells and QC, independent transgenic lines with the transcriptional fusion reporters proPLT1-CFP, proPLT2-CFP or proWOX5-GFP and the translational fusion reporter proPLT1:PLT-YFP were treated with $\mathrm{NO}_{2}-\mathrm{OA}$ or OA. As seen in Figure 4F (PLT1 promotor activity) and Figure $\mathbf{4 H}$ (PLT1 protein levels), untreated seedlings shows the highest level of PLT1 expression in the QC and stem cells, gradually decreasing the intensity in the meristematic area. No differences were observed in this expression pattern for $\mathrm{NO}_{2}$-OA-treated roots (Figures 4G, I). In the case of the transcription factor PLT2 the expression is restricted to the $\mathrm{QC}$, showing no changes in any of the treatments (Supplemental Figure 1). We analyzed the expression of QC marker proWOX5-GFP (Sarkar et al., 2007) and we observed the same expression pattern in $\mathrm{NO}_{2}-\mathrm{OA}$ compared to OA or non-treated roots (Figures 4J, K). These results show that the expression of PLT and WOX5 are not affected in roots treated with $\mathrm{NO}_{2}-\mathrm{OA}$, indicating that $\mathrm{NO}_{2}-\mathrm{FA}$ does not affect the signaling mechanisms related to stem cell niche maintenance.

A reduction in the number of cells in the meristematic zone indicates that the process of cell division is likely to be affected, and consequently the number of cells in mitosis is reduced. To confirm this, we use transgenic plants with the transcriptional fusion reporter proCYCB1.1-GUS construct. Cyclin B1.1 (CYCB1.1) is an enzyme that belongs to the cyclin family and it is expressed in the G2/M (Colón-Carmona et al., 1999). Figure 5 shows a significant reduction on the number of cells in mitosis in $\mathrm{NO}_{2}$-OA treated roots with respect to control or OA treated roots, indicating the $\mathrm{NO}_{2}-\mathrm{OA}$ is affecting cell division pace at the meristematic zone.

\section{DISCUSSION}

Nitrated fatty acids are well-described signaling molecules in animals (Batthyany et al., 2006; Freeman et al., 2008; Rubbo and Radi, 2008; Trostchansky and Rubbo, 2008; Schopfer et al., 2011). Detection of $\mathrm{NO}_{2}$-FA in plants was reported in Arabidopsis, pea, rice, and olives (Fazzari et al., 2014; MataPérez et al., 2016a; Mata-Pérez et al., 2016b). Our study focused 


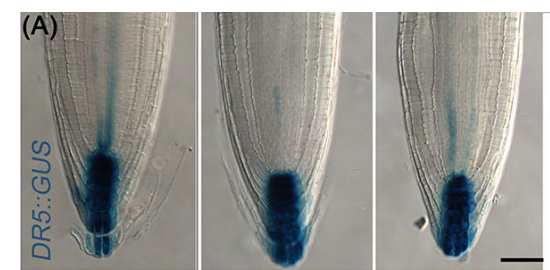

(C)
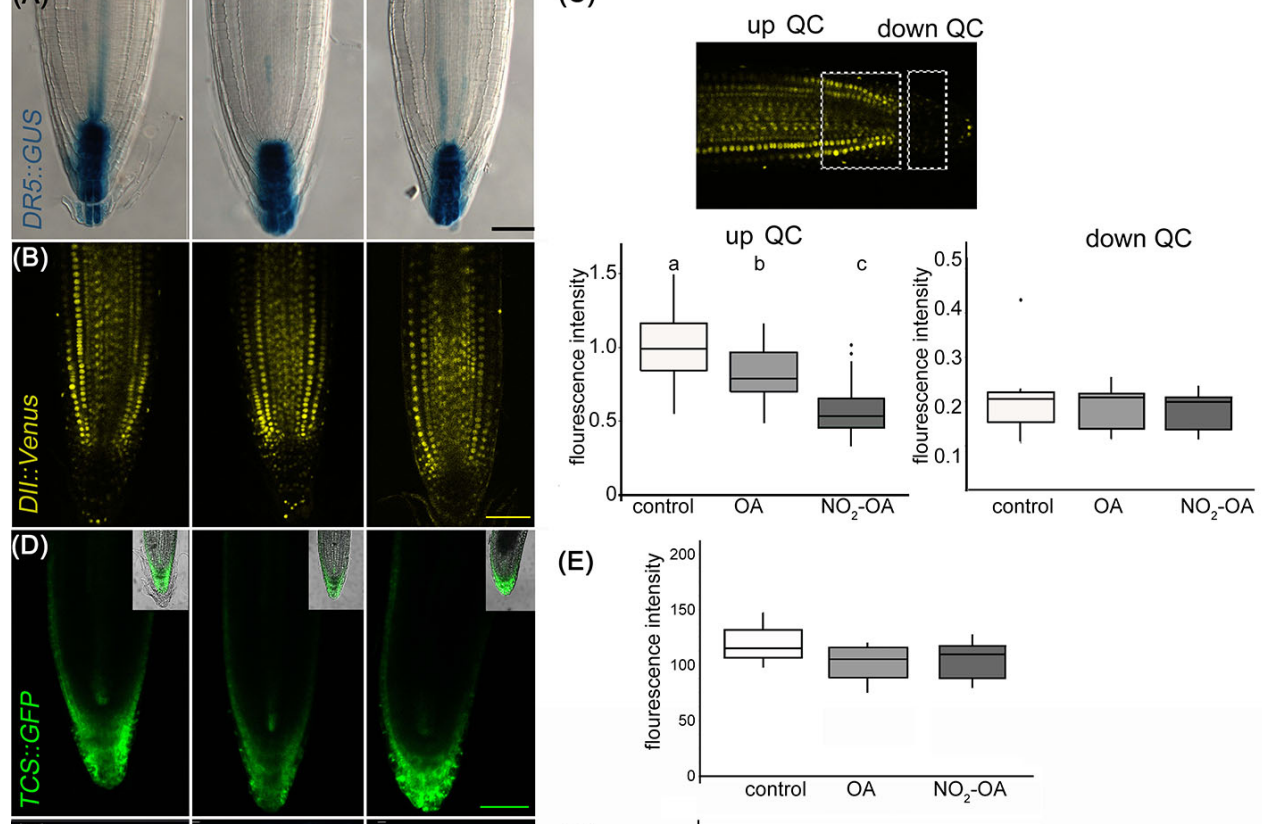

(E)
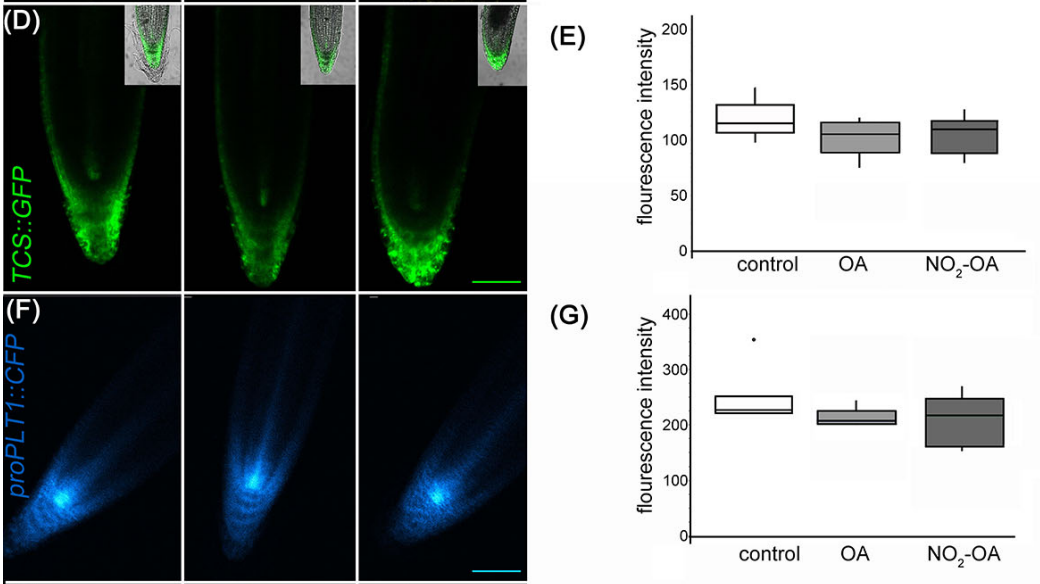

(G)
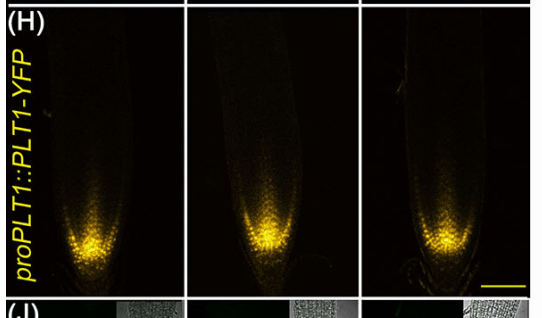

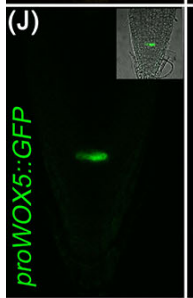

control

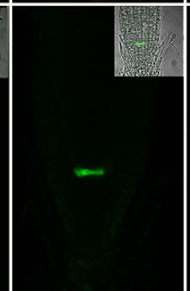

$\mathrm{OA}$
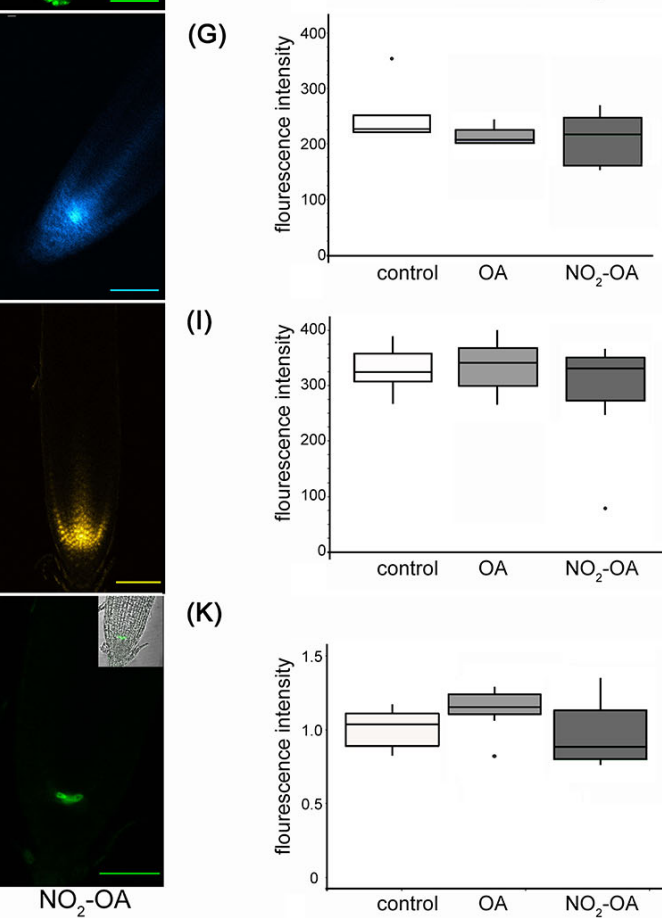

(l)

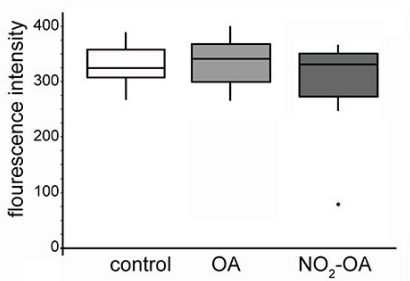

(K)

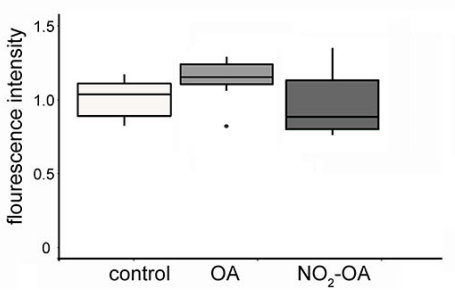

FIGURE 4 | Effect of $\mathrm{NO}_{2}$-OA on hormonal signaling. Seedlings from different reporter lines were grown for 5 days being after either not-treated or incubated with $12.5 \mu \mathrm{M}$ OA or $\mathrm{NO}_{2}$-OA for five-extra days. Representative images are shown. (A) Close-up view of GUS staining in DR5 pro:GUS seedlings. At least 15 roots were visualized of three independent experiments. (B) Confocal images of seedlings with the DII : Venus reporter line. (C) Fluorescence intensity measured at two different root zones, up which includes de QC or down quiescent center. At least 12 roots were visualized of three independent experiments. Difference letters indicate statistical significant difference (one way ANOVA, post hoc Tukey $p<0.05$ ). (D) Confocal images of seedlings with the TCS : GFP reporter line. (E) Fluorescence intensity measured from at least 12 roots from three independent experiments (one way ANOVA, post hoc Tukey $\mathrm{p}<0.05$ ). (F) Confocal images of seedlings with the proPLT1::CFP reporter line. (G) Fluorescence intensity measured from at least 12 roots from three independent experiments (one way ANOVA, post hoc Tukey $\mathrm{p}<$ 0.05). (H) Confocal images of seedlings with the proPLT1::PLT1-YFP reporter line seedlings. (I) Fluorescence intensity measured from at least 12 roots from three independent experiments (one way ANOVA, post hoc Tukey $\mathrm{p}<0.05$ ). (J) Confocal images of seedlings of proWOX5:GFP reporter line. (K) Fluorescence intensity measured from at least 10 roots from two independent experiments (one way ANOVA, post hoc Tukey $p<0.05$ ). Scale bars $=10 \mu \mathrm{m}$. The fluorescence signal intensities were quantified by using Fiji software in all the experiments. For all markers we used the same ROI (size and shape) to analyze all images of the respective experiment. 


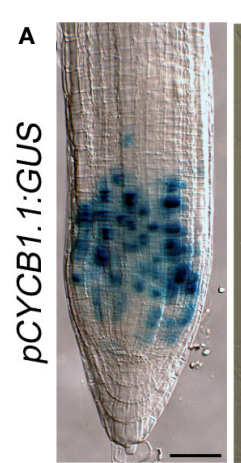

Control
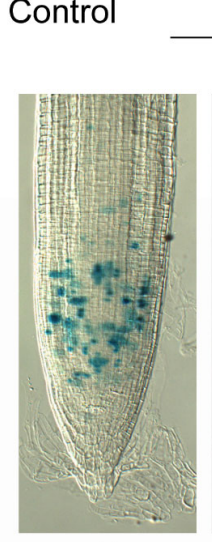

5
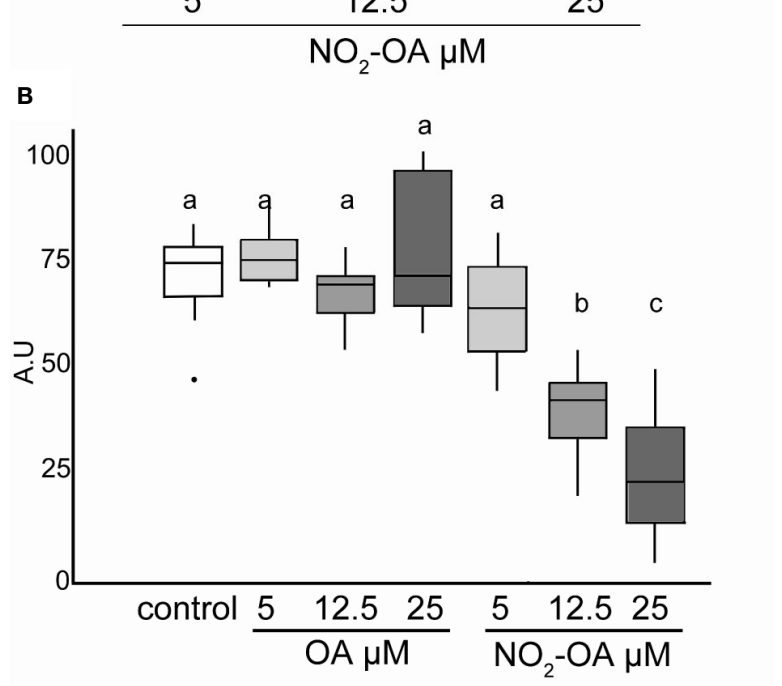

FIGURE 5 | Effect of $\mathrm{NO}_{2}$-OA on cell-division activity. Seedlings from the pCYCB1.1:GUS reporter line were grown for 5 days being after either not-treated or incubated with $25,12.5$ and $5 \mu \mathrm{M}$ OA or $\mathrm{NO}_{2}-\mathrm{OA}$ for five-extra days. (A) Representative close-up views of GUS staining are shown. Scale bars $=10 \mu \mathrm{m}$. (B) GUS staining quantification, difference letters indicated statistical significant difference, three independent experiments, $n=12-15$ (ANOVA, Tukey $p<0.05$ ).

on evaluating the role of a prototypical $\mathrm{NO}_{2}$-FA on Arabidopsis thaliana root development. Even though, in one hand, $\mathrm{NO}_{2}-\mathrm{OA}$ has not been detected in Arabidopsis thaliana either by MataPérez (2016a) and coworkers nor in this paper and, in the other hand, the precursor of this $\mathrm{NO}_{2}$-FA (oleic acid, OA) is a minority with regard the rest of unsaturated fatty acids detected along the different stages of development in Arabidopsis (Supplemental Figure S1, Mata-Pérez et al., 2016a), we decided to emulate the approach used in mammals by using the exogenous application of $\mathrm{NO}_{2}-\mathrm{OA}$, allowing us to reduce the complexity of the study and focus on its functional aspects. As mentioned earlier, in animals, $\mathrm{NO}_{2}$-OA has long been used as a surrogate to study and understand the regulation, signaling, and metabolism of $\mathrm{NO}_{2}$-FA given its additional stability and well developed synthetic routes (Freeman et al., 2008). The isomers of $\mathrm{NO}_{2}$ OA used in our experiments have been extensively characterized and correspond to an equal proportion of the 9- $\mathrm{NO}_{2}-\mathrm{OA}$ and $10-\mathrm{NO}_{2}-\mathrm{OA}$ species (Woodcock et al., 2013). Exogenous application of $\mathrm{NO}_{2}$-OA for functional studies has already been used and reported in plants. In Arabidopsis, while $\mathrm{NO}_{2}$-OA has not been detected, exogenous application of $\mathrm{NO}_{2}-$ $\mathrm{OA}$ regulates the expression of specific genes as demonstrated by qRT-PCR analysis (Mata-Pérez et al., 2016a). Moreover, in tomato and Arabidopsis, the exogenous treatment with $\mathrm{NO}_{2}$ OA triggers ROS production via NADPH oxidase activation (Arruebarrena Di Palma et al., 2020). We acknowledge the limitations of studying $\mathrm{NO}_{2}-\mathrm{OA}$ in Arabidopsis root development, as it has not been detected in the free fatty acid fraction in Arabidopsis seedlings (Mata-Pérez et al., 2016a). Nevertheless, the detection of free acid $\mathrm{NO}_{2}-\mathrm{OA}$ has been challenging as it rapidly adducts to thiol-containing proteins and glutathione, as demonstrated in mice plasma (Rudolph et al., 2010). This concept is further supported by studies in olives, where $\mathrm{NO}_{2}-\mathrm{OA}$ was found conjugated to proteins and not in the free fatty acid fraction (Fazzari et al., 2014). Recently, $\mathrm{NO}_{2}$-OA was detected in the free fatty acid fraction of Brassica seeds and seedlings, further supporting their formation and important role in plant physiology (Vollár et al., 2020). The discovery of the formation of $\mathrm{NO}_{2}$ - $\mathrm{Ln}$ in Arabidopsis seeds and seedlings and the detection of $\mathrm{NO}_{2}-\mathrm{OA}$ in Brassica supports the concept of $\mathrm{NO}_{2}-\mathrm{FA}$ as a class of signaling species in plants (Mata-Pérez et al., 2016a; Vollár et al., 2020). It is in this context that our findings of the exogenous treatment with $\mathrm{NO}_{2}$ $\mathrm{OA}$ on root development gain relevance, suggesting that $\mathrm{NO}_{2}-$ FAs have common important formation pathways and roles in seeds and seedlings in different plant species. However, the lack of endogenous detection of $\mathrm{NO}_{2}-\mathrm{OA}$ in Arabidopsis, together with the low abundance of its precursor (oleic acid, OA) with regard the rest of the unsaturated fatty acids detected in Arabidopsis seedlings (Supplemental Figure S1, Mata-Pérez et al., 2016a), remains a major stumbling block in defining the role of $\mathrm{NO}_{2}-\mathrm{OA}$ in Arabidopsis.

Here we show that exogenous application of $\mathrm{NO}_{2}-\mathrm{OA}$ inhibits the growth of the primary root in Arabidopsis. The study of different root areas showed that cell size in the elongationdifferentiation zone is not affected by $\mathrm{NO}_{2}-\mathrm{OA}$. On the other hand, roots treated with $\mathrm{NO}_{2}-\mathrm{OA}$ showed a reduction in the size of the division zone. The total number of cortex cells and the total size of the meristematic area are reduced in roots treated 
with $\mathrm{NO}_{2}-\mathrm{OA}$, indicating that the process of cell division is affected. The existing bibliography on the biological effects of Nitro Fatty acid in plants, suggest that they are acting as NO donors. In tomato cell suspensions, the exogenous treatment with $\mathrm{NO}_{2}-\mathrm{OA}$ was unable to induce NO production (Arruebarrena Di Palma et al., 2020). Interestingly, under our experimental conditions, $\mathrm{NO}_{2}-\mathrm{OA}$ is not affecting endogenous NO levels in Arabidopsis seedlings, indication that the inhibition of primary root growth by $\mathrm{NO}_{2}-\mathrm{OA}$ does not involve a $\mathrm{NO}$ dependent signaling.

Root growth is controlled by cell division and cell elongation rates. Both processes are strongly regulated by hormones, mainly auxins and cytokinins. Although auxins strongly control root growth, it has been shown that the interaction between these two signals is relevant for proper development (Dello Ioio et al., 2008). Auxins help to promote cell division and maintain the niche of stem cells and promote cytokinin biosynthesis, which consequently favors cell elongation and differentiation (Miyawaki et al., 2004; Dello Ioio et al., 2007; Dello Ioio et al., 2008). There is a strong relationship between auxin signaling and $\mathrm{NO}$ in root development. Mutants with low endogenous NO levels such as nialnia2 and noal have lower auxin endogenous concentration (Sanz et al., 2014). However, NO inhibits the transport of auxins from the stem apical meristem to the root apical meristem (Fernández-Marcos et al., 2011). The inhibitory effect on root growth by NO is related to the inhibition of the signaling cascade caused by auxins, since the reduction in DR5: GUS reporter activity is seen in the root tip, as a consequence of lower levels of expression of PIN1 proteins (Fernández-Marcos et al., 2011). Our results show that the exogenous treatment with $\mathrm{NO}_{2}$-OA has an inhibitory effect on primary root growth and is not due to an unbalance in auxin or cytokinin levels. This further supports the idea that the effect of $\mathrm{NO}_{2}$-OA on root growth is different than that reported for NO donors. An RNAseq analysis of Arabidopsis cells treated with $\mathrm{NO}_{2}-\mathrm{Ln}$, showed expression regulation of a large number of genes, but none of them related to signaling mediated by auxins or cytokinins (Mata-Pérez et al., 2016a). Consistently, our results show that $\mathrm{NO}_{2}$-OA does not affect auxins or cytokinins signaling.

Since the meristematic area is reduced, we studied the possibility that $\mathrm{NO}_{2}$-OA could affect the stem cell niche. To do so, we used the transcriptional proPLT1:CFP, proPLT2:CFP and the translational proPLT1:PLT1-CFP constructions considering PLT are transcription factors essential for QC identity and stem cell activity. The PLT genes are transcribed in response to auxin accumulation and are dependent on auxin response transcription factors. There is a correlation between PLT levels and root location, showing high levels in the division area, moderate in the transition zone and low levels in the elongation/differentiation side (Aida et al., 2004; Galinha et al., 2007). The expression levels of PLT1 and PLT2 are related to the size of the meristem. The double mutant plt1-4;plt2-2 showed a reduction in the size of the meristem and short primary root. On the other hand, overexpression of PLT2 showed an increase in the size of the meristem, particularly due to an increase in the number of cells (Aida et al., 2004; Kornet and Scheres, 2009; Mähönen et al., 2014). The expression of PLT is strongly related to cell division and the inhibition of differentiation since the expression of PLT2 in epidermal cells inhibits the formation of root hairs (Mähönen et al., 2014). Although there is a strong correlation between PLT 1 and PLT2 and auxin levels (Galinha et al., 2007), there is no decrease of DR5:GUS reporter activity in the plt1-4; plt2-2 double mutant (Aida et al., 2004; Kornet and Scheres, 2009). Roots treated with $\mathrm{NO}_{2}$-OA had shorter meristem and a lower number of cells, but this was not due to altered levels in terms of expression or location of PLT1/2. In addition, we studied the localization of the QC transcription factor WOX5. WOX5 maintains stem cells in Arabidopsis roots (Sarkar et al., 2007). WOX5 expression was no affected by $\mathrm{NO}_{2}-$ OA treatment. Visualization of PLT1, PLT2 and WOX5 allowed us discard the effect of $\mathrm{NO}_{2}$-OA treatment on those transcription factors. Together these experiments suggest that the auxin and cytokinin balance and the transcription factors PLT1, PLT2 and WOX5, which are necessary for the development and maintenance of the stem cell niche, are not affected by $\mathrm{NO}_{2}$ OA treatments. Based on the observed results in which the division area is affected but not the elongation zone, QC or stem cells, we can conclude that $\mathrm{NO}_{2}$-OA has a selective effect on the process of cell division.

The CyclinB1.1 gene codifies to a mitotic cyclin. The transcription of $C y c B 1.1$ is associated with the G2 and M phase and is a marker for active cell division (Ferreira et al., 1994b). The construction of promoter region of $C y c B 1.1$ fused with GUS is widely used to study particularly mitotic cell in different plant tissue (Colón-Carmona et al., 1999; Burssens et al., 2000). The results obtained with the $p C Y C B 1.1-G U S$ confirm that $\mathrm{NO}_{2}-\mathrm{OA}$ inhibits cell division process in a dose-dependent manner.

Nitrolipids are weak electrophiles that can bind covalently to cystein or histidine residues of protein by Michael addition and modify stability or function of proteins (Batthyany et al., 2006; Baker et al., 2007). In animal few proteins have been described to be modified by $\mathrm{NO}_{2}$-FA, being most of them related to antiinflammatory processes, such as the Nuclear factor (erythroidderived 2) -like 2 (Nrf2), peroxisome proliferator-activated receptor- $\gamma(\mathrm{PPAR} \gamma)$ and nuclear factor-kappa B (NF-kB) (Cui et al., 2006; Li et al., 2008; Kansanen et al., 2011). In plants, posttranslational modifications mediated by $\mathrm{NO}_{2}$-FA were, so far, only reported for APX (Aranda-Caño et al., 2019). In the same review by Aranda-Caño, the authors mention that they identified a high number of nitroalkylated proteins that increase in cell cultures treated with $\mathrm{NO}_{2}$-Ln. Since, it has been described that defects in the dynamics of the ACTIN cytoskeleton produce different phenotypes in root hairs and primary root (Gilliland et al., 2002; Yi et al., 2005; Kandasamy et al., 2009), it would be interesting to study whether actine can be post-translational modified by $\mathrm{NO}_{2}$-FA. For instance, recent studies show that the post-translational modification by $S$-Sulfhydration of ACT2, ACT7 and ACT8 proteins modifies the dynamics of the cytoskeleton, decreasing the levels of the filamentous with respect to the globular form of the protein causing inhibition in the growth of the primary root as well as in the length of root hairs (Li et al., 2018). In the present paper we show that exogenous treatment with $\mathrm{NO}_{2}$-OA has physiological effects on 
root development and, specifically, in the process of cell division in the meristematic zone. Further research will be needed to elucidate the endogenous presence of $\mathrm{NO}_{2}-\mathrm{OA}$ in Arabidopsis seedlings in order to establish how this $\mathrm{NO}_{2}$-FA interfere with cell division by affecting, directly, the order of actin or actin filaments, or through the regulation of other cell cycle regulating proteins.

Here we show that exogenous application of $\mathrm{NO}_{2}-\mathrm{OA}$ inhibits Arabidopsis primary root growth, inhibiting cell division in the mersitematic area, probably by interfering with mitotic processes.

\section{MATERIALS AND METHODS}

\section{Chemicals and Reagents}

$\mathrm{OA}$ was purchased from $\mathrm{Nu}$-Chek Prep (Elysian, $\mathrm{MN}$ ). $\mathrm{NO}_{2}-\mathrm{OA}$ was synthesized and purified as previously described (Bonacci et al., 2011; Woodcock et al., 2013).

\section{Plant Material and Growth Conditions}

Seeds from wild type Arabidopsis (Arabidopsis thaliana Col-0), pCYCB1;1:GUS (Colón-Carmona et al., 1999), TCS : GFP (Zürcher et al., 2013), DR5 pro:GUS (Ulmasov et al., 1997), PLT1 $1_{\text {pro: }}$ PLT1-YFP, PLT1 pro:CFP, and PLT2 $2_{\text {pro }}:$ CFP (Galinha et al., 2007), CYCB1;1 pro:GUS (Colón-Carmona et al., 1999), WOX5 pro:GFP (Sarkar et al., 2007) and DII-Venus (Brunoud et al., 2012) were surface sterilized in 35\% sodium hypochlorite, stratified for $48 \mathrm{~h}$ at $4^{\circ} \mathrm{C}$ in darkness. Seeds were germinated on vertically oriented plates containing $0.5 \times$ Murashige and Skoog (MS) salt mixture with Gamborg's vitamins $\mathrm{pH} 5.7$ and $0.8 \%$ agar, and grown at $25^{\circ} \mathrm{C}$ using a 16 -h-light $/ 8$-hdark photoperiod.

\section{Seedling Treatments}

Five-days old seedlings were transferred onto plates containing Murashige and Skoog (MS) salt mixture with Gamborg's vitamins $\mathrm{pH} 5.7$ and $0.8 \%$ agar, and grown at $25^{\circ} \mathrm{C}$ using a 16 h-light/8-h-dark photoperiod with $\mathrm{OA}, \mathrm{NO}_{2}$-OA or non-treated for other five days. Stock solutions of $\mathrm{NO}_{2}-\mathrm{OA}$ and $\mathrm{OA}$ were made fresh in sterile water (on glass containers) to reduce exposure of seedlings to solvents. Given that $50 \%$ of $\mathrm{NO}_{2}-\mathrm{OA}$ is immediately absorbed in the glass during aqueous stock preparation (Arruebarrena Di Palma et al., 2020), stocks solutions ware made at double the concentration indicated for each treatment. Then the lipids were applied to sterile MS agar, when the media was just about to get solid, and then poor on plastic plates.

\section{Measurement of Primary Root Length, Meristem Length and Cell Size}

Root length and meristem length were assessed in at least five independent experiments. Primary root length was measured using the software analysis package Fiji. For statistical, we used R software, we applied one-way ANOVA and Tukey's multiple comparison test for the experiments.
To measure number of cortex cells, meristem length and cell size, seedlings were fixed in Hoyer's solution for $30 \mathrm{~min}$. The material was observed on a Zeiss Axioplan imaging 2 microscope under DIC optics. We used Poisson's test for the experiment. Images were captured on an Axiocam HRC CCD camera (Zeiss) using the Axiovision program (version 4.2). Images analysis was performed using software package Fiji. The size of elongated cells were measured on two cells per root, on cells immediately before to the first root hair cell on six individuals per treatment.

\section{Nitric Oxide Detection on Roots}

Five-days old seedlings were transferred onto plates containing Murashige and Skoog (MS) salt mixture with Gamborg's vitamins $\mathrm{pH} 5.7$ and $0.8 \%$ agar, and grown at $25^{\circ} \mathrm{C}$ using a 16 h-light/8-h-dark photoperiod with $25 \mu \mathrm{M}$ OA or $\mathrm{NO}_{2}$-OA or non-treated for other five days. Arabidopsis-treated roots were incubated in the presence of $10 \mu \mathrm{M}$ of the fluorescent probe 4aminomethyl-2',7'-difluorofluorescein diacetate (DAF-FM DA) for $30 \mathrm{~min}$. Roots were visualized under epifluorescence microscopy (Ex/Em wavelengths $495 / 515 \mathrm{~nm}$ ). As positive control for DAF-FM DA probe, roots were treated with 100 $\mu \mathrm{M}$ SNP for $30 \mathrm{~min}$.

\section{B-Glucuronidase (GUS) Expression}

For GUS staining, Arabidopsis treated roots were incubated in GUS-staining buffer [5 mM EDTA, 0.1\% Triton X-100, $5 \mathrm{mM}$ $\left.\mathrm{K}_{4} \mathrm{Fe}(\mathrm{CN}) 6,0.5 \mathrm{mM} \mathrm{K}{ }_{3} \mathrm{Fe}(\mathrm{CN}) 6\right]$, and $1 \mathrm{mg} / \mathrm{ml} \mathrm{X-Gluc} \mathrm{(Rose}$ Scientific) in $50 \mathrm{mM} \mathrm{NaPi}$ buffer, $\mathrm{pH} \mathrm{7.0]} \mathrm{for} 3 \mathrm{~h}$ at $37^{\circ} \mathrm{C}$. Then the tissue was cleared with Hoyer's solution for $30 \mathrm{~min}$. The material was observed on a Zeiss Axioplan imaging 2 microscope under DIC optics. Images were captured on an Axiocam HRC CCD camera (Zeiss) using the Axiovision program (version 4.2). GUS staining was measure using Fiji software (Béziat et al., 2017), we defined a ROI to analyze all images of the respective experiment as described by Feraru et al. (2019).

\section{Confocal Microscopy}

Plant materials used in this study were previously described: PLT1pro:PLT1-YFP, PLT1pro:CFP, and PLT2pro:CFP (Galinha et al., 2007), CYCB1;1pro:GUS (Colón-Carmona et al., 1999), WOX5pro:GFP (Sarkar et al., 2007) and DII-Venus (Brunoud et al., 2012).

Arabidopsis roots from $p P L T 1: C F P$ y $p P L T 2: C F P$ transgenic plants were observed in confocal microscopy (Nikon Eclipse C1 Plus Ex/Em, 458/515).

Arabidopsis roots from TCS : GFP transgenic plants and WOX5pro:GFP were observed in confocal microscopy (Nikon Eclipse C1 Plus Ex/Em, 488/561) and quantified using Fiji software. We defined a ROI in the region that showed the most representative signal distribution. We used the same ROI (size and shape) to analyze all images of the respective experiment.

Arabidopsis root from PLT1pro:PLT1-YFP and DII-Venus were observed in confocal microscopy (Nikon Eclipse C1 Plus Ex/Em, 514/550). For DII-Venus marker we define two sections of the root, down QC is the calyptra zone, and up QC is the 
region above QC including $\mathrm{QC}, \mathrm{SCN}$ (stem-cell niche) and a portion of meristem as indicated in Figure 4. We used the same ROI (size and shape) to analyze all images of the respective experiment.

PLT1pro:CFP, PLT1pro:PLT1-YFP and PLT2pro:CFP fluorescence was measure using Fiji software as described by Ercoli et al. (2018).

\section{Data Analysis}

We used R software for all data analysis. The most representative images are shown throughout the article.

\section{DATA AVAILABILITY STATEMENT}

All datasets generated for this study are included in the article/ Supplementary Material.

\section{AUTHOR CONTRIBUTIONS}

$\mathrm{AL}$ and LF conceived the project. LF performed most of the experiment and analyzed the data. LF and IC performed all the confocal experiments, imaging processing and analyzing. FS and SS provide the $\mathrm{NO}_{2}$-OA and all the knowledge for exogenous application of the lipid. CG-M, AL, and FS designed and supervised the experiments and analyzed the data. LF and AL wrote the article with contributions of all the authors.

\section{REFERENCES}

Aida, M., Beis, D., Heidstra, R., Willemsen, V., Blilou, I., Galinha, C., et al. (2004). The PLETHORA genes mediate patterning of the Arabidopsis root stem cell niche. Cell 119, 109-120. doi: 10.1016/j.cell.2004.09.018

Aranda-Caño, L., Sánchez-Calvo, B., Begara-Morales, J. C., Chaki, M., Mata-Pérez, C., Padilla,, et al. (2019). Post-Translational Modification of Proteins Mediated by Nitro-Fatty Acids in Plants: Nitroalkylation. Plants 8 (4), 82. doi: 10.3390/ plants8040082

Arruebarrena Di Palma, A., Di Fino, L. M., Salvatore, S. R., D’Ambrosio, J. M., García-Mata, C., Schopfer, F. J., et al. (2020). Nitro-oleic acid triggers ROS production via NADPH oxidase activation in plants: A pharmacological approach. J. Plant Physiol. 246-247, 153128. doi: 10.1016/j.jplph.2020. 153128

Baker, P. R., Schopfer, F. J., Sweeney, S., and Freeman, B. A. (2004). Red cell membrane and plasma linoleic acid nitration products: synthesis, clinical identification, and quantitation. Proc. Natl. Acad. Sci. U.S.A. 101, 1157711582. doi: 10.1073/pnas.0402587101

Baker, L. M., Baker, P. R., Golin-Bisello, F., Schopfer, F. J., Fink, M., Woodcock, S. R., et al. (2007). Nitro-fatty acid reaction with glutathione and cysteine. Kinetic analysis of thiol alkylation by a Michael addition reaction. J. Biol. Chem. 282, 31085-31093. doi: 10.1074/jbc.M704085200

Batthyany, C., Schopfer, F. J., Baker, P. R., Duran, R., Baker, L. M., Huang, Y., et al. (2006). Reversible post-translational modification of proteins by nitrated fatty acids in vivo. J. Biol. Chem. 281, 20450-20463. doi: 10.1074/ jbc.M602814200

Benkova, E., and Hejatko, J. (2009). Hormone interactions at the root apical meristem. Plant Mol. Biol. 69, 383-396. doi: 10.1007/s11103-008-9393-6

Béziat, C., Kleine-Vehn, J., and Feraru, E. (2017). Histochemical staining of $\beta$ Glucuronidase and its spatial quantification. Methods Mol. Biol. 1497, 73-80. doi: 10.1007/978-1-4939-6469-7_8

\section{FUNDING}

This work was supported by the UNMdP, Consejo Nacional de Investigaciones Científicas y Técnicas, CONICET: PIP 219 and CONICET-NIH (to AL), Agencia Nacional de Promoción Científica y Tecnológica, ANPCyT; PICT-Raíces 2013-0800 (to $\mathrm{AL}$ ), and NIH GM125944 and DK112854 (to FS) and AHA 17GRN33660955 (to FS).

\section{ACKNOWLEDGMENTS}

We thanks to Ramiro Paris, Ramiro Rodriguez y Magdalena Vázquez for technical assistance on reporters analysis and for providing material for the DII-VENUS, WOX5, CYCB1:1 and PLT experiments.

\section{SUPPLEMENTARY MATERIAL}

The Supplementary Material for this article can be found online at: https://www.frontiersin.org/articles/10.3389/fpls.2020.01059/ full\#supplementary-material

SUPPLEMENTAL FIGURE S1 | Effect of NO2-OA on the expression of PLT2 transcription factor in Arabidopsis roots. Seedling of proPLT2::CFP reporter line were grown for 5 days and then treated with NO2-OA or OA $(12.5 \mu \mathrm{M})$ or not treated during other five days. Representative confocal images are shown. Fluorescence intensity measured from at least 12 roots from 3 independent experiments. Scale bars $=10 \mu \mathrm{m}$.

Bonacci, G., Asciutto, E. K., Woodcock, S. R., Salvatore, S. R., Freeman, B. A., and Schopfer, F. J. (2011). Gas-phase fragmentation analysis of nitrofatty acids. J. Am. Soc. Mass Spect. 22, 1534-1551. doi: 10.1007/s13361-011-0185-x

Brunoud, G., Wells, D., Oliva, M., Larrieu, A., Mirabet, V., Burrow, A. H., et al. (2012). A novel sensor to map auxin response and distribution at high spatiotemporal resolution. Nature 482, 103-106. doi: 10.1038/nature10791

Burssens, S., Himanen, K., van de Cotte, B., Beeckman, T., Van Montagu, M., Inzé, D., et al. (2000). Expression of cell cycle regulatory genes and morphological alterations in response to salt stress in Arabidopsis thaliana. Planta 5, 632-640. doi: $10.1007 /$ s004250000334

Colón-Carmona, A., You, R., Haimovitch-Gal, T., and Doerner, P. (1999). Technical advance: spatio-temporal analysis of mitotic activity with a labile cyclin-GUS fusion protein. Plant J. 20 (4), 503-508. doi: 10.1046/j.1365313x.1999.00620.x

Cui, T., Schopfer, F. J., Zhang, J., Chen, K., Ichikawa, T., Baker, P. R., et al. (2006). Nitrated fatty acids: Endogenous anti-inflammatory signaling mediators. J. Biol. Chem. 281, 35686-35698. doi: 10.1074/jbc.M603357200

Dello Ioio, R., Linhares, F. S., Scacchi, E., Casamitjana-Martinez, E., Heidstra, R., Costantino, P., et al. (2007). Cytokinins determine Arabidopsis root-meristem size by controlling cell differentiation. Curr. Biol. 17, 678-682. doi: 10.1016/ j.cub.2007.02.047

Dello Ioio, R., Nakamura, K., Moubayidin, L., Perilli, S., Taniguchi, M., Morita, M. T., et al. (2008). A genetic framework for the control of cell division and differentiation in the root meristem. Science 322, 1380-1384. doi: 10.1126/ science. 1164147

Dolan, L., Janmaat, K., Willemsen, V., Linstead, P., Poethig, S., Roberts, R., et al. (1993). Cellular organisation of the Arabidopsis thaliana root. Development 119, 71-84.

Ercoli, F., Vena, R., Goldy, C., Palatnik, J. F., and Rodriguez, R. (2018). Analysis of expression gradients of development regulators in Arabidopsis thaliana roots. Methods Mol. Biol. 1863, 3-17. doi: 10.1007/978-1-4939-8772-6_1 
Fazzari, M., Trostchansky, A., Schopfer, F. J., Salvatore, S. R., Sánchez-Calvo, B., Vitturi, D., et al. (2014). Olives and olive oil are sources of electrophilic fatty acid nitroalkenes. PloS One 9, e84884. doi: 10.1371/journal.pone.0084884

Feraru, E., Ferarua, M.II, Barbez, E., Waidmann, S., Sun, L., Gaidora, A., et al. (2019). PILS6 is a temperature-sensitive regulator of nuclear auxin input and organ growth in Arabidopsis thaliana. PNAS 116, 3893-3898. doi: 10.1073/ pnas. 1814015116

Fernández-Marcos, M., Sanz, L., Lewis, D. R., Muday, G. K., and Lorenzo, O. (2011). Nitric oxide causes root apical meristem defects and growth inhibition while reducing PIN-FORMED 1 (PIN1)-dependent acropetal auxin transport. PNAS 108, 18506-18511. doi: 10.1073/pnas.1108644108

Fernández-Marcos, M., Sanz, L., and Lorenzo, O. (2012). Nitric oxide. An emerging regulator of cell elongation during primary root growth. Plant Signaling Behav. 7 (2), 196-200. doi: 10.4161/psb.18895

Ferreira, P. C. G., Hemerly, A. S., de Almeida Engler, J., Van Montagu, M., Engler, G., and Inzé, D. (1994b). Developmental expression of the Arabidopsis cyclin gene cyc1At. Plant Cell 6, 1763-1774. doi: 10.1105/tpc.6.12.1763

Freeman, B. A., Baker, P. R., Schopfer, F. J., Woodcock, S. R., Napolitano, A., and d'Ischia, M. (2008). Nitro-fatty acid formation and signaling. J. Biol. Chem. 283, 15515-15519. doi: 10.1074/jbc.R800004200

Galinha, C., Hofhuis, H., Luijten, M., Willemsen, V., Blilou, I., Heidstra, R., et al. (2007). PLETHORA proteins as dose dependent master regulators of Arabidopsis root development. Nature 449, 1053-1057. doi: 10.1038/ nature06206

Gilliland, L. U., Kandasamy, M. K., Pawloski, L. C., and Meagher, R. B. (2002). Both vegetative and reproductive actin isovariants complement the stunted root hair phenotype of the Arabidopsis act2-1 mutation. Plant Physiol. 130, 2199-2209. doi: 10.1104/pp.014068

Grieneisen, V. A., Xu, J., Marée, A. F. M., Hogeweg, P., and Scheres, B. (2007). Auxin transport is sufficient to generate a maximum and gradient guiding root growth. Nature 449, 1008-1013. doi: 10.1038/nature06215

Heyman, J., Kumpf, R. P., and De Veylder, L. (2014). A quiescent path to plantlongevity. Trends Cell Biol. 24, 443-448. doi: 10.1016/j.tcb.2014.03.004

Kandasamy, M. K., McKinney, M. C., and Meagher, R. B. (2009). A Single Vegetative Actin Isovariant Overexpressed under the Control of Multiple Regulatory Sequences Is Sufficient for Normal Arabidopsis Development. Plant Cell 21, 701-718. doi: 10.1105/tpc.108.061960

Kansanen, E., Bonacci, G., Schopfer, F. J., Kuosmanen, S. M., Tong, K. I., Leinonen, H., et al. (2011). Electrophilic nitro-fatty acids activate NRF2 by a KEAP1 cysteine 151- independent mechanism. J. Biol. Chem. 286, 1401914027. doi: $10.1074 /$ jbc.M110.190710

Kornet, N., and Scheres, B. (2009). Members of the GCN5 histone acetyltransferase complex regulate PLETHORA-mediated root stem cell niche maintenance and transit amplifying cell proliferation in Arabidopsis. Plant Cell 21, 1070-1079. doi: 10.1105/tpc.108.065300

Li, Y., Zhang, J., Schopfer, F. J., Martynowski, D., Garcia-Barrio, M. T., Kovach, A., et al. (2008). Molecular recognition of nitrated fatty acids by PPAR gamma. Nat. Struct. Mol. Biol. 15, 865-867. doi: 10.1038/nsmb.1447

Li, J., Chen, S., Wang, X., Shi, C., Liu, H., Yang, J., et al. (2018). Hydrogen Sulfide Disturbs Actin Polymerization via S-Sulfhydration Resulting in Stunted Root Hair Growth. Plant Physiol. 178, 936-949. doi: 10.1104/pp.18.00838

Lombardo, M. C., Graziano, M., Polacco, J. C., and Lamattina, L. (2006). Nitric oxide functions as a positive regulator of root hair development. Plant Signaling Behav. 1, 28. doi: 10.4161/psb.1.1.2398

Mähönen, A. P., Ten Tusscher, K., Siligato, R., Smetana, O., Díaz-Triviño, S., Salojärvi, J., et al. (2014). PLETHORA gradient formation mechanism separates auxin responses. Nature 51, 125-129. doi: 10.1038/nature13663

Mata-Pérez, C., Sánchez-Calvo, B., Padilla, M. N., Begara-Morales, J. C., Luque, F., Melguizo, M., et al. (2016a). Nitro-fatty acids in plant signaling: nitro-linolenic acid induces the molecular chaperone network in Arabidopsis. Plant Physiol. 170, 686-701. doi: 10.1104/pp.15.01671

Mata-Pérez, C., Sánchez-Calvo, B., Begara-Morales, J. C., Padilla, M. N., Valderrama, R., Corpas, F. J., et al. (2016b). Nitric oxide release from nitrofatty acids in Arabidopsis roots. Plant Signal Behav. 11, 3-6. doi: 10.1080/ 15592324.2016.1154255

Mata-Pérez, C., Sánchez-Calvo, B., Begara-Morales, J. C., Carreras, A., Padilla, M. N., Melguizo, M., et al. (2016c). Nitro-linolenic acid is a nitric oxide donor. Nitric. Oxide - Biol. Chem. 57, 57-63. doi: 10.1016/j.niox.2016.05.003
Miyawaki, K., Matsumoto-Kitano, M., and Kakimoto, T. (2004). Expression of cytokinin biosynthetic isopentenyltransferase genes in Arabidopsis: tissue specificity and regulation by auxin, cytokinin, and nitrate. Plant J. 37, 128138. doi: 10.1046/j.1365-313X.2003.01945.x

Pagnussat, G. C., Lanteri, M. L., Lombardo, M. C., and Lamattina, L. (2004). Nitric oxide mediates the indole acetic acid induction activation of a mitogenactivated protein kinase cascade involved in adventitious root development. Plant Physiol. 135, 279-286. doi: 10.1104/pp.103.038554

Perilli, S., and Sabatini, S. (2010). Analysis of root meristem size development. Methods Mol. Biol. 655, 177-187. doi: 10.1007/978-1-60761-765-5_12

Petricka, J. J., Winter, C. M., and Benfey, P. N. (2012). Control of Arabidopsis root development. Annu. Rev. Plant Biol. 63, 563-590. doi: 10.1146/annurevarplant-042811-105501

Rubbo, H., and Radi, R. (2008). Protein and lipid nitration: role in redox signaling and injury. Biochim. Biophys. Acta 1780, 1318-1324. doi: 10.1016/j.bbagen.2008.03.007

Rubbo, H., Radi, R., Trujillo, M., Telleri, R., Kalyanaraman, B., Barnes, S., et al. (1994). Nitric oxide regulation of superoxide and peroxynitrite-dependent lipid peroxidation. Formation of novel nitrogen-containing oxidized lipid derivatives. J. Biol. Chem. 269, 26066-26075.

Rudolph, T. K., Rudolph, V., Edreira, M. M., Cole, M. P., Bonacci, G., Schopfer, F. J., et al. (2010). Nitro-fatty acids reduce atherosclerosis in apolipoprotein E-deficient mice. Arterioscler. Thromb. Vasc. Biol. 30, 938-945. doi: 10.1161/ ATVBAHA.109.201582

Sabatini, S., Heidstra, R., Wildwater, M., and Scheres, B. (2003). SCARECROW is involved in positioning the stem cell niche in the Arabidopsis root meristem. Genes Dev. 17, 354-358. doi: 10.1101/gad.252503

Sanz, L., Fernández-Marcos, M., Modrego, A., Lewis, D. R., Muday, G. K., Pollmann, S., et al. (2014). Nitric oxide plays a role in stem cell niche homeostasis through its interaction with auxin. Plant Physiol. 166, 19721984. doi: 10.1104/pp.114.247445

Sarkar, A., Luijten, M., Miyashima, S., Lenhard, M., Hashimoto, T., Nakajima, K., et al. (2007). Conserved factors regulate signalling in Arabidopsis thaliana shoot and root stem cell organizers. Nature 446, 811-814. doi: 10.1038/nature05703

Scheres, B., Wolkenfelt, H., Willemsen, V., Terlouw, M., Lawson, E., Dean, C., et al. (1994). Embryonic origin of the Arabidopsis primary root and root meristem initials. Development 120, 2475-2487. doi: 10.1199/tab.0101

Scheres, B. (2007). Stem-cell niches: nursery rhymes across kingdoms. Nat. Rev. Mol. Cell Biol. 8, 345-354. doi: 10.1038/nrm2164

Schopfer, F. J., Cipollina, C., and Freeman, B. A. (2011). Formation and signaling actions of electrophilic lipids. Chem. Rev. 111, 5997-6021. doi: 10.1021/cr200131e

Trostchansky, A., and Rubbo, H. (2008). Nitrated fatty acids: mechanisms of formation, chemical characterization, and biological properties, Free Radic. Biol. Med. 44, 1887-1896. doi: 10.1016/j.freeradbiomed.2008.03.006

Ulmasov, T., Murfett, J., Hagen, G., and Guilfoyle, T. J. (1997). Aux/IAA proteins repress expression of reporter genes containing natural and highly active synthetic auxin response elements. Plant Cell. 9 (11), 1963-1971. doi: 10.1105/tpc.9.11.1963

van den Berg, C., Willemsen, V., Hendriks, G., Weisbeek, P., and Scheres, B. (1997). Short-range control of cell differentiation in the Arabidopsis root meristem. Nature 390, 287-289. doi: 10.1038/36856

Vollár, M., Feigl, G., Oláh, D., Horváth, A., Molnár, A., Kúsz, N., et al. (2020). Nitro-Oleic Acid in Seeds and Di_erently Developed Seedlings of Brassica napus L. Plants 9 (3), 406. doi: 10.3390/plants9030406

Wolters, H., and Jürgens, G. (2009). Survival of the flexible: hormonal growth control and adaptation in plant development. Nat. Rev. Genet. 10, 305-317. doi: $10.1038 / \operatorname{nrg} 2558$

Woodcock, S. R., Bonacci, G., Gelhaus, S. L., and Schopfer, F. J. (2013). Nitrated fatty acids: synthesis and measurement. Free Radic. Biol. Med. 59, 14-26. doi: 10.1016/j.freeradbiomed.2012.11.015

Xu, J., Hofhuis, H., Heidstra, R., Sauer, M., Friml, J., and Scheres, B. (2006). A molecular framework for plant regeneration. Science 311, 385-388. doi: $10.1126 /$ science. 1121790

Yi, K., Guo, C., Chen, D., Zhao, B., Yang, B., and Ren, H. (2005). Cloning and functional characterization of a formin-like protein (AtFH8) from Arabidopsis. Plant Physiol. 138, 1071-1082. doi: 10.1104/pp.104.055665

Zürcher, E., Tavor-Deslex, D., Lituiev, D., Enkerli, K., Tarr, P. T., and Müller, B. (2013). A Robust and Sensitive Synthetic Sensor to Monitor the Transcriptional Output of the Cytokinin Signaling Network in Planta. Plant Physiol. 161, 1066-1075. doi: 10.1104/pp.112.211763 
Zürcher, E., Liu, J., di Donato, M., Geisler, M., and Muller, B. (2016). Plant development regulated by cytokinin sinks. Science 353, 1027-1030. doi: $10.1126 /$ science.aaf 7254

Conflict of Interest: The authors declare that the research was conducted in the absence of any commercial or financial relationships that could be construed as a potential conflict of interest.
Copyright (c) 2020 Di Fino, Cerrudo, Salvatore, Schopfer, Garcia-Mata and Laxalt. This is an open-access article distributed under the terms of the Creative Commons Attribution License (CC BY). The use, distribution or reproduction in other forums is permitted, provided the original author(s) and the copyright owner(s) are credited and that the original publication in this journal is cited, in accordance with accepted academic practice. No use, distribution or reproduction is permitted which does not comply with these terms. 